OPEN ACCESS

Edited by: Nicola Mumoli,

ASST Ovest Milanese, Italy

Reviewed by:

Marco Zimarino,

AsI Lanciano Vasto Chieti, Italy Roberta Assante,

University of Naples Federico II, Italy

*Correspondence:

Jinghua Liu

liujinghua@vip.sina.com

Yi Lyu

19111360001@fudan.edu.cn

Specialty section:

This article was submitted to General Cardiovascular Medicine,

a section of the journal

Frontiers in Cardiovascular Medicine

Received: 01 August 2021 Accepted: 01 September 2021 Published: 27 September 2021

Citation:

Wang S, Borah BJ, Cheng S, Li S,

Zheng Z, Gu X, Gong M, Lyu Y and Liu J (2021) Diabetes Associated With Greater Ejection Fraction Improvement After Revascularization in Patients With Reduced Ejection Fraction.

Front. Cardiovasc. Med. 8:751474. doi: $10.3389 /$ fcrm.2021.751474

\section{Diabetes Associated With Greater Ejection Fraction Improvement After Revascularization in Patients With Reduced Ejection Fraction}

\author{
Shaoping Wang ${ }^{1,2}$, Bijan J. Borah ${ }^{2,3}$, Shujuan Cheng ${ }^{1}$, Shiying Li $^{1}$, Ze Zheng ${ }^{1}$, \\ Xiaoyan $\mathrm{Gu}^{4}$, Ming Gong ${ }^{5}$, Yi Lyu ${ }^{6 *}$ and Jinghua Liu ${ }^{1 *}$ \\ ${ }^{1}$ Department of Cardiology, Beijing Institute of Heart Lung and Blood Vessel Diseases, Beijing Anzhen Hospital, Capital \\ Medical University, Beijing, China, ${ }^{2}$ Department of Health Sciences Research, Mayo Clinic, Rochester, MN, United States, \\ ${ }^{3}$ Robert D. and Patricia E. Kern Center for Science of Health Care Delivery, Mayo Clinic, Rochester, MN, United States, \\ ${ }^{4}$ Department of Echocardiography, Beijing Institute of Heart Lung and Blood Vessel Diseases, Beijing Anzhen Hospital, \\ Capital Medical University, Beijing, China, ${ }^{5}$ Department of Cardiovascular Surgery, Beijing Institute of Heart Lung and Blood \\ Vessel Diseases, Beijing Anzhen Hospital, Capital Medical University, Beijing, China, ${ }^{6}$ Department of Anesthesiology, \\ Minhang Hospital, Fudan University, Shanghai, China
}

Objectives: To investigate the association between diabetes mellitus (DM) and ejection fraction (EF) improvement following revascularization in patients with coronary artery disease (CAD) and left ventricular (LV) dysfunction.

Background: Revascularization may improve outcomes of patients with LV dysfunction by improvement of EF. However, the determinants of EF improvement have not yet been investigated comprehensively.

Method: A cohort study (No. ChiCTR2100044378) of patient with repeated EF measurements after revascularization was performed. All patients had baseline EF $\leq 40 \%$. Patients who had EF reassessment 3 months after revascularization were enrolled. Patients were categorized into EF unimproved (absolute increase in EF $\leq 5 \%$ ) and improved group (absolute increase in EF $>5 \%$ ).

Results: A total of 974 patients were identified. 573 (58.8\%) had EF improved. Patients with DM had greater odds of being in the improved group (odds ratio [OR], 1.42; 95\% Cl, 1.07-1.89; $P=0.014) .333(34.2 \%)$ patients with DM had a greater extent of EF improvement after revascularization (10.5 \pm 10.4 vs. $8.1 \pm 11.2 \% ; P=0.002)$ compared with non-diabetic patients. The median follow-up time was 3.5 years. DM was associated with higher risk of overall mortality (hazard ratio $[\mathrm{HR}], 1.46 ; 95 \% \mathrm{Cl}$, 1.02-2.08; $P=0.037)$. However, in EF improved group, the risk was similar between diabetic and non-diabetic patients ( $\mathrm{HR}, 1.36 ; 95 \% \mathrm{Cl}, 0.80-2.32 ; P=0.257)$.

Conclusions: Among patients with reduced EF, DM was associated with greater EF improvement after revascularization. Revascularization in diabetic patients might partially attenuate the impact of DM on adverse outcomes. Our findings imply the indication for revascularization in patients with LV dysfunction who present with DM.

Keywords: diabetes mellitus, ejection fraction, heart failure, revascularization, prognosis 


\section{INTRODUCTION}

Ischemic etiology is consistently reported as a risk factor for lack of ejection fraction (EF) improvement among patients with heart failure (HF) (1-3). Revascularization including coronary artery bypass grafting (CABG) (4) and percutaneous coronary intervention (PCI) (5-7) may improve long-term outcome by attenuating the ischemic state and reversing left ventricular (LV) remodeling for patients with ischemic HF (8-10). However, the extent and determinants of EF improvement have not been well-investigated $(9,11-14)$.

The presence of myocardial viability has been shown to be predictive of $\mathrm{EF}$ improvement after coronary revascularization $(11,15,16)$. However, not all patients with viable myocardium show an improvement of EF. In different studies, about $12 \%$ (16) to $64 \%$ (11) patients remained EF unimproved after revascularization. Besides myocardial viability, patients with more extensive coronary artery disease (CAD) and worse myocardial dysfunction and remodeling may receive greater benefit from revascularization (17).

Diabetic patients are associated with the decreased utilization of glucose and the increase in myocardial free fatty acids, occurring as a consequence of the mismatch between blood supply and cardiac metabolic requirements (18). These metabolic changes are responsible both for the increased susceptibility of the diabetic heart to myocardial ischemia and for a greater decrease of myocardial performance for a given amount of ischemia, compared to non-diabetic hearts. However, the association between diabetic status and EF improvement following revascularization has not been addressed. We hypothesize that in diabetic patients with LV dysfunction, the effects of revascularization could even give greater benefit than in non-diabetic patients.

Therefore, this study was performed to clarify (1) the determinants of EF improvement after revascularization in patients with preoperative $\mathrm{EF} \leq 40 \%$; (2) extent of $\mathrm{EF}$ improvement following revascularization in patients with vs. without DM; (3) outcomes difference between diabetic and non-diabetic patients after revascularization in a large clinical cohort with LV dysfunction.

\section{MATERIALS AND METHODS}

\section{Patient Selection}

This was a real-world retrospective cohort study that used data from Beijing Anzhen Hospital, which is a large referral hospital in China that focuses on heart, lung, and blood vessel diseases. The study was registered in Chinese Clinical Trial Registry (No. ChiCTR2100044378).The study protocol was approved by the hospital's ethics committee.

CAD patients with reduced $\mathrm{EF}(\leq 40 \%)$ who underwent CABG or PCI with a drug-eluting stent between January 2005

\footnotetext{
Abbreviations: $\mathrm{CABG}$, coronary artery bypass grafting; CAD, coronary artery disease; DM, diabetes mellitus; EF, ejection fraction; eGFR, estimated glomerular filtration rate; $\mathrm{HbAlc}$, hemoglobin $\mathrm{Alc}$; $\mathrm{HF}$, heart failure; $\mathrm{HR}$, hazard ratio; $\mathrm{LV}$, left ventricular; MI, myocardial infarction; $\mathrm{MR}$, mitral regurgitation; OR, odds ratio; PCI, percutaneous coronary intervention.
}

and December 2014, and with repeated EF measurements during follow-up were enrolled. Patients were excluded if they had concomitant non-coronary surgery, were diagnosed as ST-segment elevation myocardial infarction, had only one record of EF follow-up reassessment within 3 months after revascularization. The final study sample included patients who had EF reassessment by echocardiography 3 months after revascularization. Patients were then categorized according to the absolute change in EF: (1) EF unimproved group (absolute increase in $\mathrm{EF} \leq 5 \%$ ); (2) $\mathrm{EF}$ improved group (absolute increase in $\mathrm{EF}>5 \%$ ) (19). Patients with $\mathrm{EF}$ unimproved were further categorized: (1) EF worsened group (absolute decrease in EF $>5 \%$ ); (2) EF unchanged group (absolute change in $\mathrm{EF}-5$ to $5 \%)(19)$.

\section{Data Collection and Definitions}

Baseline demographic, clinical, laboratory, and angiographic parameters for the study patients were ascertained from Beijing Anzhen Hospital medical records. Baseline EF was captured within 30 days before PCI or CABG. Follow-up EF values were defined as the first EF measurement 3 months (20) after revascularization assessed in Beijing Anzhen Hospital. Complete revascularization was defined as successful PCI (residual stenosis of $<30 \%$ ) of all angiographically significant lesions ( $\geq 70 \%$ diameter stenosis) in 3 coronary arteries and their major branches. A staged procedure within 90 days after discharge was acceptable. For CABG, grafting of every primary coronary artery with $\geq 70 \%$ diameter stenosis was accepted as complete revascularization.

Outcome data were obtained from medical records at Beijing Anzhen Hospital and through telephone follow up. Death was regarded as cardiovascular in origin unless obvious non-cardiovascular causes could be identified. Any death during hospitalization for repeat coronary revascularization was regarded as cardiovascular death. The follow-up time (19, $21,22)$ for patients started at the time of the first available EF measurement.

\section{Statistical Analysis}

Only patients with non-missing covariates were included in the study; thus, missing data were not imputed. Continuous variables were expressed as mean (SD) and categorical variables as counts (percentages). Highly skewed continuous distributions were described by median (interquartile range). Baseline characteristics were compared between the EF improved and unimproved groups as well as groups with and without DM by using a student $t$-test, rank sum test, or $\chi^{2}$ test, as appropriate. Multivariate logistic regression was used to identify independent correlates of EF improvement. Variables of demographics and history, preoperative echocardiography values, angiography and therapies as well as clinical chemistry were included in the analysis. All variables that had marginal association in univariate analysis $(P<0.100)$ were adopted as independent variables in multivariate logistic regression analysis. Cumulative incidences were estimated by the Kaplan-Meier method and compared by log-rank test. The risks of outcomes were analyzed with a Cox proportional hazards regression model. The proportional 
TABLE 1 | Patient characteristics at baseline ${ }^{a}$ (EF improved vs. EF unimproved patients).

\begin{tabular}{|c|c|c|c|c|}
\hline Characteristics & $\begin{array}{l}\text { All patients } \\
(n=974)\end{array}$ & $\begin{array}{l}\text { Improved } \\
(n=573)\end{array}$ & $\begin{array}{l}\text { Unimproved } \\
\qquad(n=401)\end{array}$ & $P$-value \\
\hline \multicolumn{5}{|l|}{ Demographics and history } \\
\hline Age, y & $64.7(10.9)$ & $64.8(11.0)$ & $64.6(10.7)$ & 0.766 \\
\hline Men & $813(83.5)$ & 475 (82.9) & 338 (84.3) & 0.565 \\
\hline Weight, kg & $72.0(11.1)$ & $71.7(11.1)$ & $72.6(11.0)$ & 0.212 \\
\hline eGFR, mL/min/1.73m² & $85.0(24.3)$ & $85.4(23.8)$ & $84.4(24.9)$ & 0.529 \\
\hline DM & $333(34.2)$ & $216(37.7)$ & $117(29.2)$ & 0.006 \\
\hline Insulin-dependent DM & $78(8.1)$ & $46(8.2)$ & $32(8.1)$ & 0.951 \\
\hline Cerebral vascular disease & $70(7.2)$ & $37(6.5)$ & $33(8.2)$ & 0.292 \\
\hline Atrial fibrillation & $45(4.6)$ & $25(4.4)$ & $20(5.0)$ & 0.648 \\
\hline \multicolumn{5}{|l|}{ Echocardiography } \\
\hline \multicolumn{5}{|l|}{ Preoperative } \\
\hline$E F, \%$ & $36.3(4.3)$ & $35.8(4.7)$ & $36.9(3.6)$ & $<0.001$ \\
\hline MR (moderate or severe) & $166(17.0)$ & 95 (16.6) & $71(17.7)$ & 0.645 \\
\hline \multicolumn{5}{|l|}{ Postoperative } \\
\hline$E F, \%$ & $45.2(11.2)$ & $52.0(8.6)$ & $35.4(6.2)$ & $<0.001$ \\
\hline MR (moderate or severe) & $149(15.3)$ & $55(9.6)$ & $94(23.4)$ & $<0.001$ \\
\hline Change of EF, \% & $8.9(11.0)$ & $16.2(7.5)$ & $-1.5(5.4)$ & $<0.001$ \\
\hline \multicolumn{5}{|l|}{ Angiography and therapy } \\
\hline Multi-vessel disease & $769(79.0)$ & 456 (79.6) & $313(78.1)$ & 0.565 \\
\hline Left main disease & $58(6.0)$ & $35(6.1)$ & $23(5.7)$ & 0.809 \\
\hline
\end{tabular}

CABG, coronary artery bypass grafting; DM, diabetes mellitus; EF, ejection fraction; eGFR, estimated glomerular filtration rate; MI, myocardial infarction; MR, mitral regurgitation; PCI, percutaneous coronary intervention.

a Values are mean (SD) or No. of patients (\%).

hazards assumption was tested for individual covariates and globally on the basis of Schoenfeld residuals. All statistical analyses were based on 2-tailed tests. $P<0.05$ was considered statistically significant. Statistical analyses were performed with Stata version 14.0 (StataCorp).

\section{RESULTS}

\section{Baseline Characteristics of EF Improved vs. Unimproved Patients}

Among 1,816 initially identified patients, 78 patients who died within 3 months after revascularization, 764 patients were further excluded because EF was not evaluated 3 months after revascularization.

This study cohort included 974 patients who had an initial $\mathrm{EF} \leq 40 \%$ and had echocardiography reassessment 3 months after revascularization. The average age at baseline was 64.7 \pm 10.9 years (Table 1). Men comprised $83.5 \%$ of all subjects. 556 (57.1\%) received PCI and 418 (42.9\%) underwent CABG.
After revascularization, 573 (58.8\%) had LVEF improved and $401(41.2 \%)$ remained unimproved. Mean (SD) EF improved significantly, from $35.8 \%(4.7 \%)$ to $52.0 \%(8.6 \%)$, in the $\mathrm{EF}$ improved group $(P<0.001)$ and remained reduced $(36.9 \%$ [3.6\%] to $35.4 \%$ [5.8\%]; $P<0.001)$ in the unimproved group. The mean duration between the preoperative and follow-up EF measurements in two groups was comparable (improved group: $5.9 \pm 2.6$ months vs. unimproved group: $6.3 \pm 2.8$ months; $P$ $=0.113$ ).

Age at baseline and sex distribution were similar between the EF improved group and EF unimproved group (Table 1). The EF improved group had a significantly higher prevalence of DM (37.7 vs. $29.2 \% ; P=0.006)$ and lower prevalence of history of myocardial infarction (MI) before revascularization (41.5 vs. $53.4 \% ; P<0.001)$. The EF improved group had a significantly higher postoperative EF $(52.0 \pm 8.6$ vs. $35.4 \pm$ 6.2\%; $P<0.001)$, but lower preoperative $\mathrm{EF}(35.8 \pm 4.7$ vs. 36.9 $\pm 3.6 \% ; P<0.001)$. The anatomic severity of coronary artery disease was similar between the groups. There was no significant 
TABLE 2 | Baseline factors associated with EF improvement following revascularization in a multivariate model.

\begin{tabular}{|c|c|c|c|c|}
\hline Variables & \multicolumn{2}{|c|}{ Univariate analysis } & \multicolumn{2}{|c|}{ Multivariate analysis } \\
\hline Age & $1.00(0.99-1.01)$ & 0.766 & & \\
\hline Male sex & $0.90(0.64-1.28)$ & 0.565 & & \\
\hline Weight & $0.99(0.98-1.00)$ & 0.212 & & \\
\hline Current smoker & $1.02(0.78-1.34)$ & 0.863 & & \\
\hline eGFR & $1.00(1.00-1.01)$ & 0.529 & & \\
\hline Cerebral vascular disease & $0.77(0.47-1.25)$ & 0.293 & & \\
\hline History of Ml & $0.62(0.48-0.80)$ & $<0.001$ & $0.63(0.48-0.82)$ & 0.001 \\
\hline Atrial fibrillation & $0.87(0.48-1.59)$ & 0.648 & & \\
\hline History of $\mathrm{PCl}$ & $0.74(0.53-1.03)$ & 0.075 & $0.86(0.61-1.21)$ & 0.396 \\
\hline Preoperative EF & $0.94(0.91-0.97)$ & $<0.001$ & $0.94(0.91-0.97)$ & $<0.001$ \\
\hline $\mathrm{PCl}^{*}$ & $1.05(0.81-1.36)$ & 0.702 & & \\
\hline Complete revascularization & $0.86(0.66-1.11)$ & 0.238 & & \\
\hline
\end{tabular}

${ }^{*} C A B G$ was set as reference to $P C l$.

TABLE 3 | Patient characteristics at baseline ${ }^{a}$ (diabetic vs. non-diabetic patients).

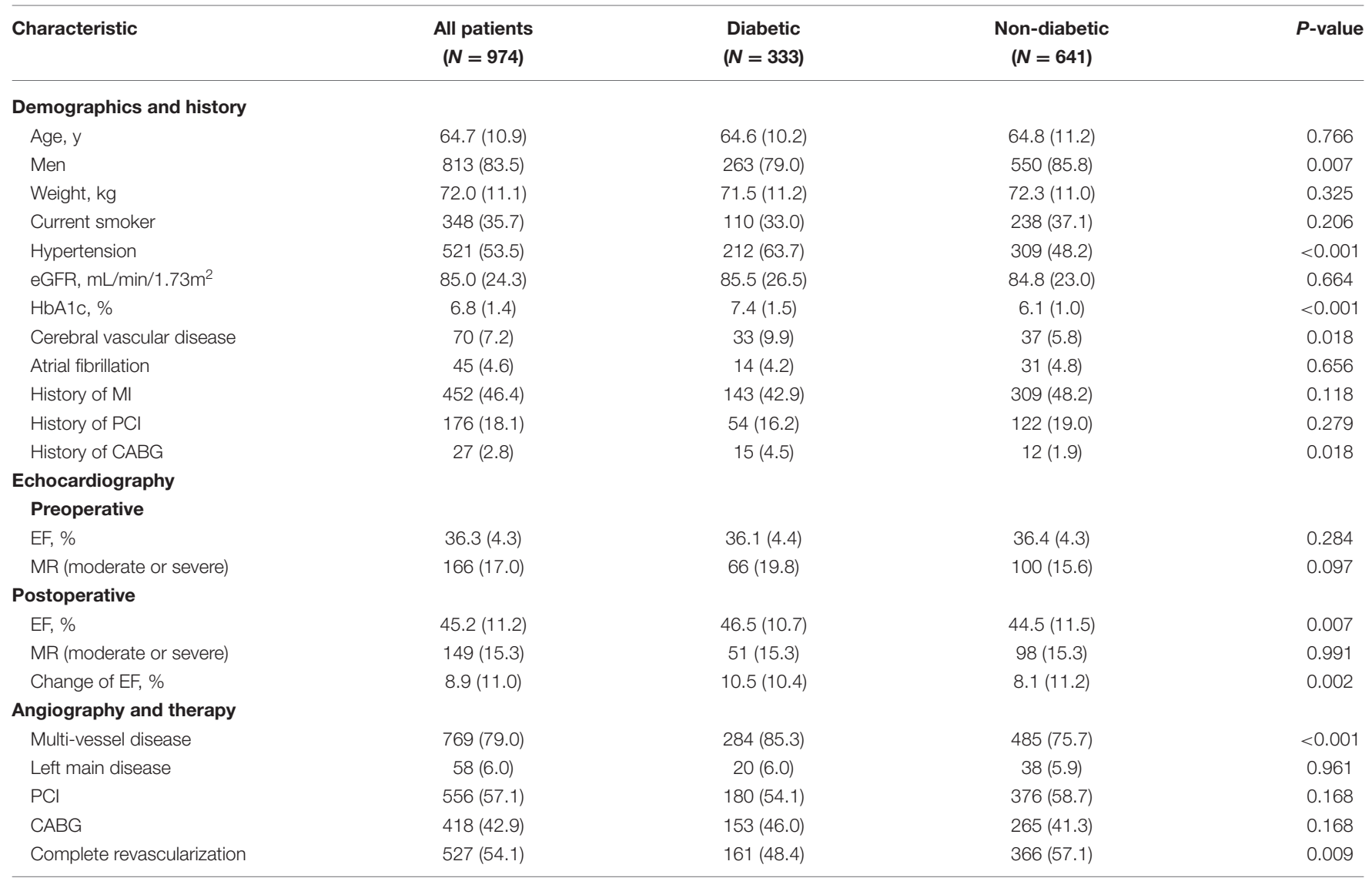

CABG, coronary artery bypass grafting; DM, diabetes mellitus; EF, ejection fraction; eGFR, estimated glomerular filtration rate; HbA1c, hemoglobin A1c; MI, myocardial infarction; MR, mitral regurgitation; $\mathrm{PCl}$, percutaneous coronary intervention.

${ }^{a}$ Values are mean (SD) or No. of patients (\%). 
difference in the proportions undergoing revascularization by PCI or CABG, and the groups had similar percentages of complete revascularization.

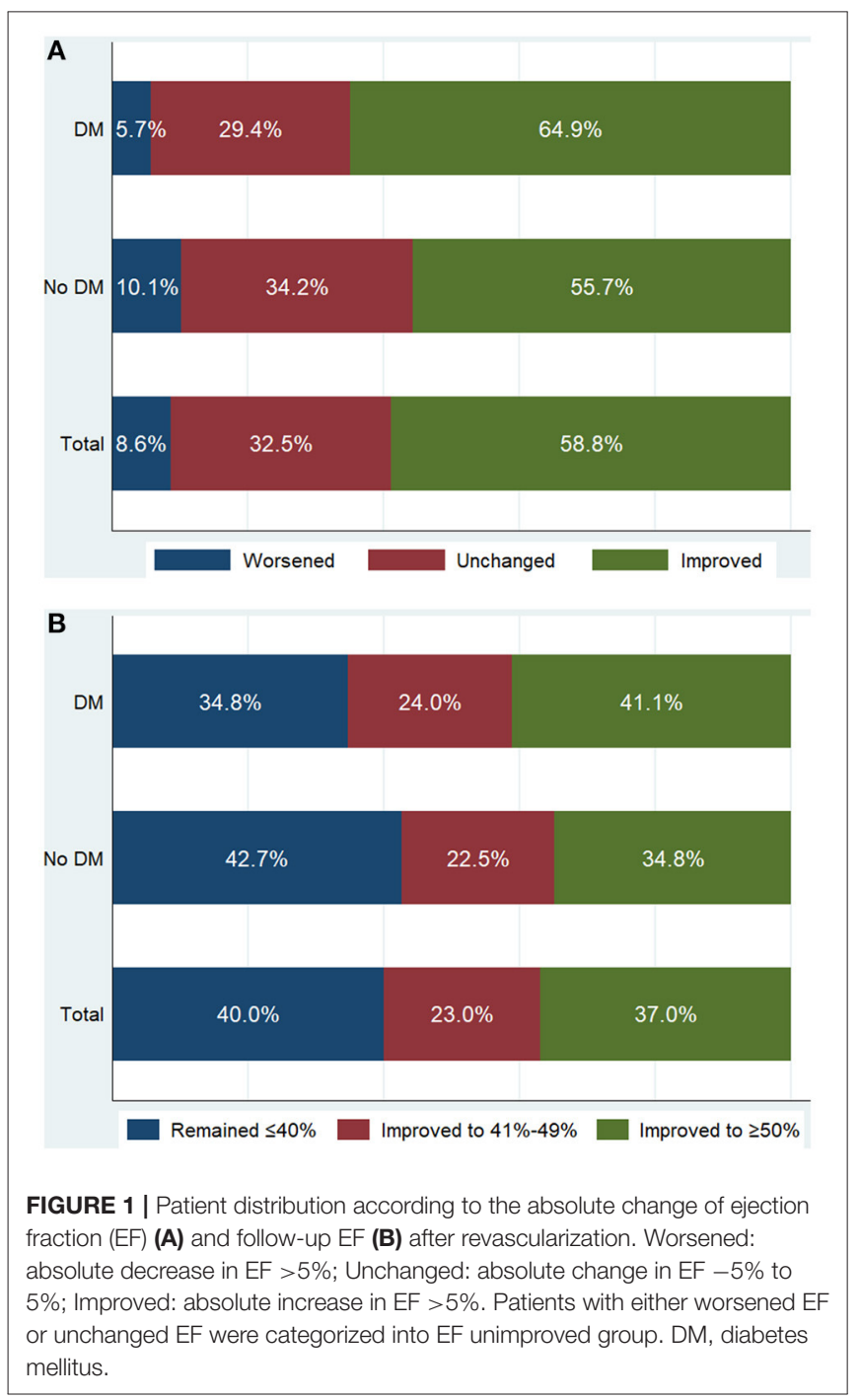

\section{Predictors of EF Improvement}

Evaluation for independent predictors of $\mathrm{EF}$ improvement showed that patients with DM had greater odds of being in the improved group (odds ratio [OR], 1.42; 95\% CI, 1.07-1.89; $P=0.014)$ (Table 2). Patients with a history of MI (OR, 0.63; 95\% CI, 0.48-0.82; $P=0.001)$ and with higher preoperative EF (OR per $1 \%$ increase in EF, 0.94; 95\% CI, 0.91-0.97; $P<0.001$ ) had lower odds of being in the EF improved group. Neither anatomic severity of coronary vessels (as indicated by multivessel disease and left main disease) nor extent of revascularization (complete vs. incomplete) was an independent correlate of EF improved.

\section{Baseline Characteristics of Diabetic Patients vs. Non-diabetic Patients}

To further clarify the characteristics of DM patients, all patients were further categorized according to the status of DM (Table 3 ). $333(34.2 \%)$ had DM with a mean (SD) hemoglobin A1c of $7.4 \%(1.5 \%)$. The proportions of male patients were lower in diabetic group ( 79.0 vs. $85.8 \% ; P=0.007$ ). Diabetic patients had a significantly higher prevalence of hypertension (63.7 vs. $48.2 \% ; P<0.001$ ) and cerebral vascular disease (9.9 vs. $5.8 \% ; P$ $=0.018)$. Diabetic patients had a significantly higher prevalence of multivessel disease (85.3 vs. $75.7 \%$; $P<0.001$ ), but lower percentages of complete revascularization (48.4 vs. $57.1 \%$; $P=$ 0.009 ). The proportions undergoing revascularization by PCI or CABG was similar between two groups $(P=0.168)$.

Compared with non-diabetic patients, diabetic patients had a similar preoperative $\mathrm{EF}(36.1 \pm 4.4$ vs. $36.4 \pm 4.3 \%$; $P=$ $0.284)$, but had a significantly higher postoperative EF (46.5 \pm 10.7 vs. $44.5 \pm 11.5 \%$; $P=0.007)$, which resulted in a greater extent of EF improvement after revascularization (10.5 \pm 10.4 vs. $8.1 \pm 11.2 \% ; P=0.002$ ) (Table 3 ). After revascularization, in 333 diabetic patients, EF measurements were worsened in 19 (5.7\%), unchanged in 98 (29.4\%), and improved in $216(64.9 \%)$ (Figure 1A). Diabetic patients were more likely to experience EF improvement compared to non-diabetic patients $(P=0.008)$. After revascularization, $137(41.1 \%)$ diabetic patients had an EF that improved to $\geq 50 \%$, 80 (24.0\%) improved to $41-49 \%$, and $116(34.8 \%)$ remained $\leq 40 \%$ (Figure 1B). Diabetic patients

TABLE 4 | Risk of outcomes (diabetic vs. non-diabetic patients).

\begin{tabular}{|c|c|c|c|c|c|c|}
\hline \multirow[t]{2}{*}{ Outcomes } & \multicolumn{2}{|c|}{$\begin{array}{c}\text { Total } \\
(N=974)\end{array}$} & \multicolumn{2}{|c|}{$\begin{array}{c}\text { EF improved } \\
\qquad(N=573)\end{array}$} & \multicolumn{2}{|c|}{$\begin{array}{l}\text { EF unimproved } \\
\qquad(N=401)\end{array}$} \\
\hline & HR $(95 \%$ Cl) & $P$-value & HR $(95 \%$ Cl) & $P$-value & HR $(95 \%$ CI) & $P$-value \\
\hline \multicolumn{7}{|c|}{ All-cause death } \\
\hline DM & $1.46(1.02-2.08)$ & 0.037 & $1.36(0.80-2.32)$ & 0.257 & $1.82(1.13-2.94)$ & 0.014 \\
\hline No DM & Ref & & Ref & & Ref & \\
\hline DM & $1.48(1.02-2.22)$ & 0.046 & $1.42(0.77-2.64)$ & 0.262 & $1.82(1.07-3.08)$ & 0.026 \\
\hline No DM & Ref & & Ref & & Ref & \\
\hline
\end{tabular}

$D M$, diabetes mellitus; $E F$, ejection fraction; $H R$, hazard ratio; Ref, reference. 


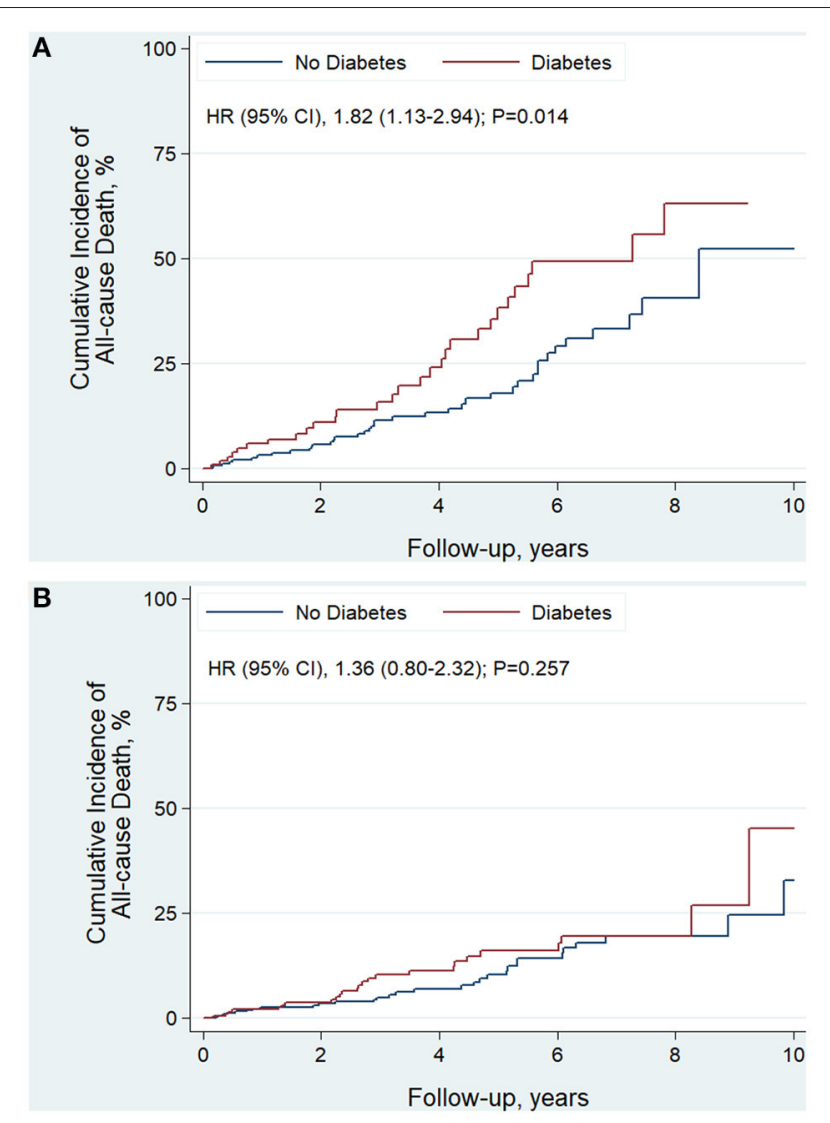

FIGURE 2 | Kaplan-Meier curves estimating incidence of all-cause death after revascularization in EF unimproved group (A) and EF improved group (B): diabetic vs. non-diabetic patients.

were more likely to have higher EF distribution compared to non-diabetic patients $(P=0.049)$.

\section{Outcomes of Diabetic Patients vs. Non-diabetic Patients}

The median follow-up time was 3.5 years. In EF improved group, there were 55 patients died and 41 were cardiovascular death. In the EF unimproved group, there were 69 patients died and 57 were cardiovascular death. EF improvement was associated with lower risk of all-cause death (HR, 0.45; 95\% CI, 0.32-0.64; $P<0.001)$ and cardiovascular death (HR, 0.41; 95\% CI, 0.27-0.61; $P<0.001)$. For diabetic status, patient with DM had significantly higher risk of all-cause death (HR, 1.46; 95\% CI, 1.02-2.08; $P=0.037)$ and cardiovascular death (HR, 1.48; 95\% CI, 1.02-2.22; $P=0.046$ ) (Table 4). This finding persisted in EF unimproved group (Table 4 and Figure 2A). However, in EF improved group, both all-cause mortality (HR, 1.36; 95\% CI, 0.80-2.32; $P=0.257$ ) and cardiovascular mortality (HR, 1.42; 95\% CI, 0.77-2.64; $P=0.262$ ) were similar between diabetic and non-diabetic patients (Table 4 and Figure 2B).

\section{DISCUSSION}

In the current study, EF measurements 3 months after revascularization were used to define the patient cohorts with EF improved or EF unimproved. The literature has not addressed the issue of EF evolution over time after revascularization (12, 14). Three months after revascularization might be necessary allowing for the LV to recover from CABG surgery or PCI procedure and for ischemic myocardium to fully reverse remodeling after revascularization and medical therapy (20). According this definition, about $60 \%$ CAD patients with reduced $\mathrm{EF}(\leq 40 \%)$ had LVEF improved (absolute increase in $\mathrm{EF}>5 \%$ ) following revascularization by either PCI or CABG, which indicated the benefit of revascularization in patients with $\mathrm{LV}$ dysfunction. Patients with EF improved had significantly lower risk of overall and cardiovascular death compared to those with EF unimproved.

In the current study, without history of MI, lower preoperative $\mathrm{EF}$ and DM were identified as three independent predictors of EF improvement after revascularization among patients with LV dysfunction. Patients who had history of MI are more likely to have scarred and non-viable myocardium compared to patients without history of MI. Thus, patients with history of MI might benefit less from revascularization and had lower odds to have EF improved. The multicenter Surgical Treatment for Ischemic Heart Failure (STICH) trial (23) compared the efficacy of medical therapy alone with that of medial therapy plus CABG in patients with LV dysfunction (EF $\leq 35 \%$ ). Preoperative $\mathrm{EF}<27 \%$ was one of three prognostic factors which associated with greater survival benefit from CABG (17). This result consisted with current finding and supported the indication for revascularization in patients with worse myocardial dysfunction.

Besides history of $\mathrm{MI}$ and preoperative EF, more important finding in this study is that DM was firstly identified, to our knowledge, as a factor associated with greater EF improvement after revascularization. Patients with DM have an impaired myocardial metabolism and increased cardiac cell death with its attendant fibrosis, which causing an accelerated and diffused atherosclerosis (18). Clinical studies in the scenario of ACS have shown evidences of a higher susceptibility of diabetic patients to such things as greater risk for the development of heart failure and higher morbidity and mortality rate (24-26). However, by treatments targeting those pathogenetic factors caused by $\mathrm{DM}$, diabetic patients may benefit more than non-diabetic patients. In diabetic patients with ischemic LV dysfunction, modulation of free fatty acids metabolism could give greater benefits of decreasing the incidence of angina attacks than in non-diabetic patients (27). The addition of direct renin inhibitor aliskiren to standard therapy was associated with trends toward greater reduction in LV size among diabetic compared with non-diabetic subjects who had history of MI and EF $\leq 45 \%$ (28). An invasive strategy appeared to reduce recurrent non-fatal MI to a greater extent in patients with DM and non-ST-segment elevation acute coronary syndromes (29). In current study, DM was found as an independent correlate of greater EF improvement among patients with LV dysfunction who underwent revascularization. Revascularization is a direct 
strategy to reverse the mismatch between blood supply and cardiac metabolic requirements in ischemic heart. This mismatch was more severe in diabetic compared with non-diabetic myocardium, which therefore may result in greater improvement of EF by revascularization. In our patient cohort, DM was associated with greater EF improvement. In EF improved group, diabetic patients had similar risk of overall and cardiovascular mortality compared with non-diabetic patients. In contrast, in EF unimproved group, DM was associated with higher risk of both overall and cardiovascular death. This indicated that greater EF improvement by revascularization in diabetic patients at least partially attenuated the impact of DM on adverse outcomes.

Completeness of revascularization achieved with CABG is associated with a bigger number of treated lesions and a more percentage of successful complete revascularization when compared to a PCI strategy. A large pooled analysis of over 5,000 diabetic patients with stable CAD demonstrated the benefit of completeness of revascularization and long-term patency of $\mathrm{CABG}$, which provides protection from subsequent reinfarction likely contributing to the survival advantage (30). In the current study, despite the high prevalence of multivessel diseases, the incidence of $\mathrm{CABG}$ tended to be lower than that of PCI in both diabetic and non-diabetic group. Diabetic patients had a significantly higher prevalence of multivessel disease, but lower percentages of complete revascularization. Extent of revascularization (complete vs. incomplete) was not an independent correlate of EF improvement. Whether the severity of LV dysfunction and/or extent of coronary disease would affect the revascularization strategic decision-making, and the benefit of complete revascularization needs to be further clarified.

This was a non-randomized, observational study from a single center. Therefore, as with any observational study, ours also suffered from selection biases. In this study, only EF measurements that were obtained by echocardiography in one hospital were used for comparison, since institutions and specific methods for measuring EF vary. This restriction improved the accuracy of the EF measurements but increased the number of excluded patients. The median follow-up time of the study was

\section{REFERENCES}

1. Florea VG, Rector TS, Anand IS, Cohn JN. Heart failure with improved ejection fraction: clinical characteristics, correlates of recovery, and survival: results from the valsartan heart failure trial. Circ Heart Fail. (2016) 9:3123. doi: 10.1161/CIRCHEARTFAILURE.116.003123

2. Kalogeropoulos AP, Fonarow GC, Georgiopoulou V, Burkman G, Siwamogsatham S, Patel A, et al. Characteristics and outcomes of adult outpatients with heart failure and improved or recovered ejection fraction. JAMA Cardiol. (2016) 1:510-8. doi: 10.1001/jamacardio.2016.1325

3. Wilcox JE, Fonarow GC, Yancy CW, Albert NM, Curtis AB, Heywood JT, et al. Factors associated with improvement in ejection fraction in clinical practice among patients with heart failure: findings from IMPROVE HF. Am Heart J. (2012) 163:49-56.e2. doi: 10.1016/j.ahj.2011.10.001

4. Velazquez EJ, Lee KL, Jones RH, Al-Khalidi HR, Hill JA, Panza JA, et al. Coronary-artery bypass surgery in patients with ischemic cardiomyopathy. $\mathrm{N}$ Engl J Med. (2016) 374:1511-20. doi: 10.1056/NEJMoa1602001

5. Yang JH, Choi SH, Song YB, Hahn JY, Choi JH, Jeong DS, et al. Long-term outcomes of drug-eluting stent implantation versus coronary
3.5 years. Taking into account the natural slow evolution of the disease and its related complications, relative short time period of follow-up is another limitation. In addition, we highlighted that the impact of DM on outcomes in this study was actually evaluated among patients who are survivors 3 months at least after PCI or CABG because each patients had EF reassessment at least 3 months after revascularization.

\section{CONCLUSION}

The current study indicates that $\sim 60 \%$ of patients with preoperative $\mathrm{EF} \leq 40 \%$ are likely to have absolute $\mathrm{EF}$ improved ( $>5 \%$ ) after revascularization. DM was an independent predictor of EF improvement and associated with greater EF improvement. Revascularization in diabetic patients might partially attenuate the impact of DM on adverse outcomes. Our findings imply the indication for revascularization in patients with $\mathrm{LV}$ dysfunction who present with DM.

\section{DATA AVAILABILITY STATEMENT}

The raw data supporting the conclusions of this article will be made available by the authors, without undue reservation.

\section{ETHICS STATEMENT}

The studies involving human participants were reviewed and approved by Ethics Committee of Beijing Anzhen Hospital. Written informed consent for participation was not required for this study in accordance with the national legislation and the institutional requirements.

\section{AUTHOR CONTRIBUTIONS}

JL and YL conceived the concept of the study and supervision. SW contributed to the design of the research and wrote the original-draft. All authors were involved in data collection and analysis, edited, and approved the final version of the manuscript.

artery bypass grafting for patients with coronary artery disease and chronic left ventricular systolic dysfunction. Am J Cardiol. (2013) 112:6239. doi: 10.1016/j.amjcard.2013.04.035

6. Lee DH, Jeong MH, Rhee JA, Choi JS, Lee KH, Lee MG, et al. Predictors of long-term survival in acute coronary syndrome patients with left ventricular dysfunction after percutaneous coronary intervention. Korean Circ J. (2012) 42:692-7. doi: 10.4070/kcj.2012.42.10.692

7. Kunadian V, Pugh A, Zaman AG, Qiu W. Percutaneous coronary intervention among patients with left ventricular systolic dysfunction: a review and meta-analysis of 19 clinical studies. Coron Artery Dis. (2012) 23:469-79. doi: 10.1097/MCA.0b013e32835 87804

8. Michler RE, Rouleau JL, Al-Khalidi HR, Bonow RO, Pellikka PA, Pohost $\mathrm{GM}$, et al. Insights from the STICH trial: change in left ventricular size after coronary artery bypass grafting with and without surgical ventricular reconstruction. J Thorac Cardiovasc Surg. (2013) 146:113945.e6. doi: 10.1016/j.jtcvs.2012.09.007

9. Vakil K, Florea V, Koene R, Kealhofer JV, Anand I, Adabag S. Effect of coronary artery bypass grafting on left ventricular ejection fraction in 
men eligible for implantable cardioverter-defibrillator. Am J Cardiol. (2016) 117:957-60. doi: 10.1016/j.amjcard.2015.12.029

10. Adachi Y, Sakakura K, Wada H, Funayama H, Umemoto T, Fujita H, et al. Determinants of left ventricular systolic function improvement following coronary artery revascularization in heart failure patients with reduced ejection fraction (HFrEF). Int Heart J. (2016) 57:56572. doi: 10.1536/ihj.16-087

11. Bax JJ, Poldermans D, Elhendy A, Cornel JH, Boersma E, Rambaldi $\mathrm{R}$, et al. Improvement of left ventricular ejection fraction, heart failure symptoms and prognosis after revascularization in patients with chronic coronary artery disease and viable myocardium detected by dobutamine stress echocardiography. J Am Coll Cardiol. (1999) 34:163-9. doi: 10.1016/S0735-1097(99)00157-6

12. Funaro S, La Torre G, Madonna M, Galiuto L, Scara A, Labbadia A, et al. Incidence, determinants, and prognostic value of reverse left ventricular remodelling after primary percutaneous coronary intervention: results of the Acute Myocardial Infarction Contrast Imaging (AMICI) multicenter study. Eur Heart J. (2009) 30:566-75. doi: 10.1093/eurheartj/ehn529

13. Rizzello V, Poldermans D, Biagini E, Schinkel AF, Boersma E, Boccanelli A, et al. Prognosis of patients with ischaemic cardiomyopathy after coronary revascularisation: relation to viability and improvement in left ventricular ejection fraction. Heart. (2009) 95:1273-7. doi: 10.1136/hrt.2008.163972

14. Yoo JS, Kim JB, Jung SH, Choo SJ, Chung CH, Lee JW. Coronary artery bypass grafting in patients with left ventricular dysfunction: predictors of long-term survival and impact of surgical strategies. Int J Cardiol. (2013) 168:5316-22. doi: 10.1016/j.ijcard.2013.08.009

15. Cuocolo A, Petretta M, Nicolai E, Pace L, Bonaduce D, Salvatore $\mathrm{M}$, et al. Successful coronary revascularization improves prognosis in patients with previous myocardial infarction and evidence of viable myocardium at thallium-201 imaging. Eur J Nucl Med. (1998) 25:608. doi: $10.1007 / \mathrm{s} 002590050195$

16. Ragosta M, Beller GA, Watson DD, Kaul S, Gimple LW. Quantitative planar rest-redistribution $201 \mathrm{Tl}$ imaging in detection of myocardial viability and prediction of improvement in left ventricular function after coronary bypass surgery in patients with severely depressed left ventricular function. Circulation. (1993) 87:1630-41. doi: 10.1161/01.CIR.87.5.1630

17. Panza JA, Velazquez EJ, She L, Smith PK, Nicolau JC, Favaloro RR, et al. Extent of coronary and myocardial disease and benefit from surgical revascularization in ischemic LV dysfunction [Corrected]. J Am Coll Cardiol. (2014) 64:553-61. doi: 10.1016/j.jacc.2014.04.064

18. Barsotti A, Giannoni A, Di Napoli P, Emdin M. Energy metabolism in the normal and in the diabetic heart. Curr Pharm Des. (2009) 15:83640. doi: 10.2174/138161209787582066

19. Zhang Y, Guallar E, Blasco-Colmenares E, Butcher B, Norgard S, Nauffal V, et al. Changes in follow-up left ventricular ejection fraction associated with outcomes in primary prevention implantable cardioverter-defibrillator and cardiac resynchronization therapy device recipients. J Am Coll Cardiol. (2015) 66:524-31. doi: 10.1016/j.jacc.2015.05.057

20. Russo AM, Stainback RF, Bailey SR, Epstein AE, Heidenreich PA, Jessup M, et al. ACCF/HRS/AHA/ASE/HFSA/SCAI/SCCT/SCMR 2013 appropriate use criteria for implantable cardioverter-defibrillators and cardiac resynchronization therapy: a report of the American College of Cardiology Foundation appropriate use criteria task force, Heart Rhythm Society, American Heart Association, American Society of Echocardiography, Heart Failure Society of America, Society for Cardiovascular Angiography and Interventions, Society of Cardiovascular Computed Tomography, and Society for Cardiovascular Magnetic Resonance. J Am Coll Cardiol. (2013) 61:131868. doi: 10.1016/j.jacc.2012.12.017

21. Stankovic I, Belmans A, Prinz C, Ciarka A, Maria Daraban A, Kotrc M, et al. The association of volumetric response and long-term survival after cardiac resynchronization therapy. Eur Heart J Cardiovasc Imaging. (2017) 18:1109-17. doi: 10.1093/ehjci/jex188

22. Stankovic I, Prinz C, Ciarka A, Daraban AM, Kotrc M, Aarones M, et al. Relationship of visually assessed apical rocking and septal flash to response and long-term survival following cardiac resynchronization therapy (PREDICT-CRT). Eur Heart J Cardiovasc Imaging. (2016) 17:2629. doi: 10.1093/ehjci/jev288

23. Velazquez EJ, Lee KL, Deja MA, Jain A, Sopko G, Marchenko A, et al. Coronary-artery bypass surgery in patients with left ventricular dysfunction. N Engl J Med. (2011) 364:1607-16. doi: 10.1056/NEJMoa1100356

24. Mukamal KJ, Nesto RW, Cohen MC, Muller JE, Maclure M, Sherwood $\mathrm{JB}$, et al. Impact of diabetes on long-term survival after acute myocardial infarction: comparability of risk with prior myocardial infarction. Diabetes Care. (2001) 24:1422-7. doi: 10.2337/diacare.24.8.1422

25. Stone PH, Muller JE, Hartwell T, York BJ, Rutherford JD, Parker $\mathrm{CB}$, et al. The effect of diabetes mellitus on prognosis and serial left ventricular function after acute myocardial infarction: contribution of both coronary disease and diastolic left ventricular dysfunction to the adverse prognosis. The MILIS Study Group. J Am Coll Cardiol. (1989) 14:4957. doi: 10.1016/0735-1097(89)90053-3

26. Murcia AM, Hennekens CH, Lamas GA, Jimenez-Navarro M, Rouleau JL, Flaker GC, et al. Impact of diabetes on mortality in patients with myocardial infarction and left ventricular dysfunction. Arch Intern Med. (2004) 164:22739. doi: 10.1001/archinte.164.20.2273

27. Barsotti A, Di Napoli P. [Trimetazidine and cardioprotection during ischemia-reperfusion]. Ital Heart J. (2004) 5(Suppl. 2):29S-36.

28. Shah AM, Shin SH, Takeuchi M, Skali H, Desai AS, Kober L, et al. Left ventricular systolic and diastolic function, remodelling, and clinical outcomes among patients with diabetes following myocardial infarction and the influence of direct renin inhibition with aliskiren. Eur J Heart Fail. (2012) 14:185-92. doi: 10.1093/eurjhf/ hfr125

29. O’Donoghue ML, Vaidya A, Afsal R, Alfredsson J, Boden WE, Braunwald E, et al. An invasive or conservative strategy in patients with diabetes mellitus and non-ST-segment elevation acute coronary syndromes: a collaborative meta-analysis of randomized trials. J Am Coll Cardiol. (2012) 60:106-11. doi: 10.1016/j.jacc.2012.02.059

30. Mancini GB, Farkouh ME, Brooks MM, Chaitman BR, Boden WE, Vlachos $\mathrm{H}$, et al. Medical treatment and revascularization options in patients with type 2 diabetes and coronary disease. J Am Coll Cardiol. (2016) 68:98595. doi: 10.1016/j.jacc.2016.06.021

Conflict of Interest: The authors declare that the research was conducted in the absence of any commercial or financial relationships that could be construed as a potential conflict of interest.

Publisher's Note: All claims expressed in this article are solely those of the authors and do not necessarily represent those of their affiliated organizations, or those of the publisher, the editors and the reviewers. Any product that may be evaluated in this article, or claim that may be made by its manufacturer, is not guaranteed or endorsed by the publisher.

Copyright (C) 2021 Wang, Borah, Cheng, Li, Zheng, Gu, Gong, Lyu and Liu. This is an open-access article distributed under the terms of the Creative Commons Attribution License (CC BY). The use, distribution or reproduction in other forums is permitted, provided the original author(s) and the copyright owner(s) are credited and that the original publication in this journal is cited, in accordance with accepted academic practice. No use, distribution or reproduction is permitted which does not comply with these terms. 